\title{
HIMPUNAN LEMBUT KABUR HESITANT DIPERUMUM DAN APLIKASINYA DALAM PENGAMBILAN KEPUTUSAN
}

\author{
GANDUNG CATUR WICAKSONO \\ Jurusan Matematika, \\ Fakultas Matematika dan Ilmu Pengetahuan Alam, Universitas Andalas, \\ Kampus UNAND Limau Manis Padang, Indonesia, \\ email : gandungcatur12@gmail.com
}

\begin{abstract}
Abstrak. Dalam kehidupan sehari-hari terdapat permasalahan yang mengandung unsur ketidakpastian atau keragu-raguan. Molodstov memperkenalkan sebuah teori baru yaitu teori himpunan lembut yang digunakan untuk mengatasi unsur ketidakpastian atau keragu-raguan. Teori himpunan lembut ini dapat dikombinasikan dengan beberapa teori seperti teori himpunan kabur yang diperkenalkan oleh Zadeh. Pada tulisan ini akan dibahas mengenai kombinasi dari himpunan kabur hesitant diperumum dengan teori himpunan lembut serta memperkenalkan konsep dari himpunan lembut kabur hesitant diperumum. Selanjutnya diberikan operasi-operasi beserta beberapa sifatnya yang berlaku pada himpunan lembut kabur hesitant diperumum, serta bagaimana pengaplikasiannya dalam pengambilan suatu keputusan.
\end{abstract}

Kata Kunci: Himpunan lembut, himpunan kabur, himpunan lembut kabur, himpunan kabur intuitionistik, himpunan lembut kabur intuitionistik, himpunan kabur hesitant, himpunan kabur hesitant diperumum, himpunan lembut kabur hesitant diperumum

\section{Pendahuluan}

Prof.L.A.Zadeh pada tahun 1965 pertama kali memperkenalkan teori baru yaitu teori himpunan kabur. Zadeh [1] mendefinisikan suatu himpunan fuzzy atas X sebagai koleksi dari pasangan terurut $(\mathrm{x}, \mu(x)), \forall x \in X$ dimana derajat keanggotaan $\mu(x) \in[0,1]$.

Molodtsov [9] juga mengusulkan suatu teori baru yang dinamakan dengan teori himpunan lembut (soft set theory). Teori ini berguna untuk mengatasi permasalahan yang mengandung unsur ketidakpastian dan keragu-raguan, seperti pada pengambilan keputusan, teori pengukuran, dan teori permainan.

Selanjutnya, Chen [12] berfikir bahwa terkadang nilai pada derajat keanggotaan yang diberikan tidak bisa hanya satu saja dan tidak bisa hanya memperhitungkan derajat keanggotaannya, namun derajat non keanggotaannya juga harus dipertimbangkan pada interval [0,1]. Oleh karena itu, Chen [12] dan kawan-kawan berdiskusi untuk memperluas himpunan kabur hesitant (hesitant fuzzy sets) dan himpunan kabur intuitionistik (intuitionistik fuzzy set) sehingga diperkenalkan konsep dari himpunan kabur hesitant diperumum (generalized hesitant fuzzy sets).

Oleh sebab itu diperlukan kajian lebih lanjut mengenai gabungan dari himpunan kabur hesitant diperumum dengan teori himpunan lembut dan memperkenalkan 
konsep dari himpunan lembut kabur hesitant diperumum (generalized hesitant fuzzy soft sets).

\section{Landasan Teori}

Definisi 2.1. [7] Misalkan $U$ adalah himpunan semesta, $P(U)$ adalah suatu himpunan kuasa atas $U, E$ adalah suatu himpunan parameter dan $A \subseteq$ E. Maka himpunan lembut (soft set) $F_{A}$ atas $U$ adalah himpunan yang didefinisikan oleh fungsi $f_{A}$ yang dapat disajikan dalam himpunan pasangan terurut

$$
F_{A}=\left\{\left(x, f_{A}(x)\right): x \in E, f_{A} \in P(U)\right\}
$$

dimana $f_{A}: A \rightarrow P(U)$ sedemikian sehingga $f_{A}(x)=\emptyset$ jika $x \notin A$.

\subsection{Himpunan Kabur Hesitant Diperumum ( Generalized Hesitant Fuzzy Set)}

Definisi 2.2. [11] Misalkan $X=\left\{x_{1}, x_{2}, \cdots, x_{n}\right\}$ suatu himpunan. Suatu himpunan kabur hesitant diperumum $G$ pada $X$ dapat dinyatakan sebagai :

$$
G:=\left\{\frac{x}{(h(x), g(x))} \mid x \in X\right\}:=\left\{\frac{x}{G(x)} \mid x \in X\right\}
$$

dimana $h(x)$ dan $g(x)$ merupakan himpunan dari beberapa nilai-nilai yang pada selang $[0,1]$, yang menotasikan derajat keanggotaan dan non keanggotaan yang memungkinkan dari $x \in X$ pada $G$, dengan $0 \leq \mu_{i}(x), \nu_{i}(x) \leq 1,0 \leq \mu_{i}(x)+\nu_{i}(x) \leq$ $1,1 \leq i \leq N_{x}=|h(x)|=|g(x)|$, dimana $\mu_{i}(x) \in h(x), \nu_{i}(x) \in g(x), \forall x \in X$, dan $|h(x)|$ dinotasikan sebagai banyaknya anggota himpunan $h(x) . G(x)=(h(x), g(x))$ disebut generalized hesitant fuzzy element atau bisa dinotasikan dengan $G=(h, g)$.

Definisi 2.3. [11] Misalkan G adalah himpunan kabur hesitant diperumum, komplemen dari $G$ dapat dinyatakan sebagai:

$$
G^{c}(x)=\bigcup_{\mu_{i}(x) \in h(x), \nu_{i}(x) \in g(x)}\left\{\left(\left\{\nu_{i}(x)\right\},\left\{\mu_{i}(x)\right\}\right)\right\} .
$$

Definisi 2.4. [11] Diberikan dua himpunan kabur hesitant diperumum, $G_{1}=$ $\left\{\frac{x}{\left(h_{1}(x), g_{1}(x)\right)}\right\}$ dan $G_{2}=\left\{\frac{x}{\left(h_{2}(x), g_{2}(x)\right)}\right\}$, maka didefinisikan beberapa operasi sebagai berikut.

(1) $G_{1} \cup G_{2}(x)=\left\{(\mu(x), \nu(x)), \mu(x) \in h_{1}(x) \cup h_{2}(x) \mid \mu(x) \geq \max \left(h_{1}^{-}(x)\right.\right.$, $\left.\left.h_{2}^{-}(x)\right), \nu(x) \in\left(g_{1}(x) \cup g_{2}(x)\right) \mid \nu(x) \leq \min \left(g_{1}^{+}(x), g_{2}^{+}(x)\right)\right\}$

(2) $G_{1} \cap G_{2}(x)=\left\{(\mu(x), \nu(x)), \mu(x) \in h_{1}(x) \cup h_{2}(x) \mid \mu(x) \geq \min \left(h_{1}^{+}(x)\right.\right.$, $\left.\left.h_{2}^{+}(x)\right), \nu(x) \in\left(g_{1}(x) \cup g_{2}(x)\right) \mid \nu(x) \leq \max \left(g_{1}^{-}(x), g_{2}^{-}(x)\right)\right\}$.

dimana notasi + menyatakan nilai terbesar dari hesitant fuzzy element dan menyatakan nilai terkecil dari hesitant fuzzy element.

Perhatikan nilai-nilai dari generalized hesitant fuzzy element yang berbeda-beda. Misalkan $\left|h_{M}(x)\right|$ menyatakan banyaknya elemen di $h_{M}(x)$. Selanjutnya, diasumsikan : 
(1) Semua element dari $h_{M}(x)$ disusun dengan urutan menaik.

(2) Jika untuk suatu $x \in X,\left|h_{M}(x)\right| \neq\left|h_{N}(x)\right|$, maka $l_{x}=\max \left\{\left|h_{M}(x)\right|, \mid\right.$ $\left.h_{N}(x) \mid\right\}$. Untuk mendapatkan perbandingan antara $h_{M}(x)$ dan $h_{N}(x)$ yang wajar, maka dua generalized hesitant fuzzy element $h_{M}(x)$ dan $h_{N}(x)$ harus memiliki banyaknya anggota yang sama. Jika banyaknya element $h_{M}(x)$ lebih sedikit dari $h_{N}(x)$, maka banyaknya anggota ditambah sampai sebanyak $l_{x}$.

Definisi 2.5. [11] Misalkan $M$ dan $N$ adalah himpunan kabur hesitant diperumum atas $X$. M dikatakan generalized hesitant fuzzy subset atas $N$, jika untuk suatu $x \in X, 1 \leq i \leq l_{x}$, maka $\mu_{i}^{M}(x) \leq \mu_{i}^{N}(x)$ dan $\nu_{i}^{M}(x) \geq \nu_{i}^{N}(x)$. Dapat dinotasikan dengan $M \sqsubseteq N$.

Definisi 2.6. [11] Untuk suatu himpunan kabur hesitant diperumum $G, s(h)=$ $\frac{1}{|h|} \cdot \sum_{\gamma \in h} \gamma$ dan $s(h)=\frac{1}{|g|} \cdot \sum_{\eta \in h} \eta$ adalah fungsi score dari $h$ dan $g$, dimana $|h|$ dan $|g|$ mewakili banyaknya elemen-elemen pada $h$ dan $g$.

\section{Himpunan Lembut Kabur Hesitant Diperumum (Generalized Hesitant Fuzzy Soft Sets)}

Dalam kehidupan sehari-hari terkadang sulit untuk memberikan nilai yang tepat terhadap suatu gagasan dengan menggunakan beberapa angka yang tegas pada interval [0.1], oleh karena itu Chen [12] dan kawan-kawan berdiskusi untuk memperluas himpunan kabur hesitant (hesitant fuzzy sets dan memperkenalkan konsep dari himpunan kabur hesitant diperumum (generalized hesitant fuzzy sets). Untuk itu pada bab ini, akan diperkenalkan konsep dari himpunan lembut kabur hesitant diperumum, yang merupakan gabungan dari himpunan kabur hesitant diperumum dengan teori himpunan lembut.

Definisi 3.1. [12] Misalkan $U$ adalah himpunan semesta, E adalah himpunan parameter, $A \subseteq E$ dan $G H F^{U}$ adalah himpunan dari semua himpunan kabur hesitant diperumum atas $U$, maka pasangan $(\widetilde{G}, A)$ disebut himpunan lembut kabur hesitant diperumum atas $U$, dimana

$$
\widetilde{G}: A \rightarrow G H F^{U} .
$$

Suatu himpunan lembut kabur hesitant diperumum merupakan suatu pemetaan dari himpunan parameter $A$ ke $G H F^{U}$. Misalkan e $\in$ A, maka $\widetilde{G}(\mathrm{e})$ merupakan peta dari elemen e pada suatu himpunan kabur hesitant diperumum. $\widetilde{G}(\mathrm{e})$ juga dapat ditulis sebagai,

$$
\widetilde{G}\left(e_{i}\right)=\left\{\frac{x}{\left(\mu_{i}(x), \nu_{i}(x)\right)} \mid x \in U\right\}, \quad i=1,2, \cdots, n
$$

dengan $\mu_{i}(x), \nu_{i}(x)$ merupakan suatu HFE atas $x$, dimana HFE memiliki beberapa nilai-nilai derajat keanggotaan atau non keanggotaan yang memungkinkan. Sehingga, $\mu_{i}(x)$ adalah himpunan dari beberapa nilai-nilai yang merupakan derajat keanggotaan dari himpunan kabur hesitant diperumum dan $\nu_{i}(x)$ adalah himpunan dari beberapa nilai-nilai yang merupakan derajat non keanggotaan dari himpunan kabur hesitant diperumum. 
Definisi 3.2. [12] Suatu himpunan lembut kabur hesitant diperumum $(\widetilde{F}, A)$ dikatakan himpunan lembut kabur hesitant diperumum kosong yang dinotasikan dengan $\Phi_{A}$, jika $h_{\widetilde{F}(e)}(x)=0$ dan $g_{\widetilde{F}(e)}(x)=1$, untuk setiap e $\in A$.

Definisi 3.3. [12] Suatu himpunan lembut kabur hesitant diperumum $(\widetilde{F}, A)$ dikatakan himpunan lembut kabur hesitant diperumum penuh yang dinotasikan dengan $\Omega_{A}$, jika $h_{\widetilde{F}(e)}(x)=1$ dan $g_{\widetilde{F}(e)}(x)=0$, untuk setiap $e \in A$.

Definisi 3.4. [12] Suatu himpunan lembut kabur hesitant diperumum $(\widetilde{F}, A)$ atas $U$, untuk suatu $e \in A$ dan $x \in U$. Himpunan lembut kabur intuitionistik $(F, A)$ atas $U$ dikatakan reduksi pesimis dari himpunan lembut kabur intuitionistik atas $(\widetilde{F}, A)$ jika $\mu(x)=h_{\widetilde{F}(e)}^{-}(x)$ dan $\nu(x)=g_{\widetilde{F}(e)}^{+}(x)$ atas $\widetilde{F}(e)$, dimana notasi + menyatakan nilai terbesar dari hesitant fuzzy element dan - menyatakan nilai terkecil dari hesitant fuzzy element.

Definisi 3.5. [12] Suatu himpunan lembut kabur hesitant diperumum $(\widetilde{F}, A)$ atas $U$, untuk suatu $e \in A$ dan $x \in U$. Himpunan lembut kabur intuitionistik $(F, A)$ atas $U$ dikatakan reduksi optimis dari himpunan lembut kabur intuitionistik atas $(\widetilde{F}, A)$ jika $\mu(x)=h_{\widetilde{F}(e)}^{+}(x)$ dan $\nu(x)=g_{\widetilde{F}(e)}^{-}(x)$ atas $\widetilde{F}(e)$, dimana notasi + menyatakan nilai terbesar dari hesitant fuzzy element dan - menyatakan nilai terkecil dari hesitant fuzzy element.

Definisi 3.6. [12] Suatu himpunan lembut kabur hesitant diperumum $(\widetilde{F}, A)$ atas $U$, untuk suatu $e \in A$ dan $x \in U$. Himpunan lembut kabur intuitionistik $(F, A)$ atas $U$ dikatakan reduksi netral dari himpunan lembut kabur intuitionistik atas $(\widetilde{F}, A)$ jika $\mu(x)=s\left(h_{\widetilde{F}(e)}(x)\right)$ dan $\nu(x)=s\left(g_{\widetilde{F}(e)}(x)\right)$ atas $\widetilde{F}(e)$, dimana notasi + menyatakan nilai terbesar dari hesitant fuzzy element dan - menyatakan nilai terkecil dari hesitant fuzzy element.

\subsection{Operasi pada Himpunan Lembut Kabur Hesitant Diperumum}

Definisi 3.7. [12] Misalkan $\widetilde{G}\left(e_{i}\right)=\left\{\frac{x}{\left(\mu_{i}(x), \nu_{i}(x)\right)} \mid x \in U\right\}$ dengan $i=1,2, \cdots, n$ dan $t=1,2, \cdots, m$. Fungsi complement dari $\widetilde{G}\left(e_{i}\right)$ didefinisikan sebagai

$$
\left(\widetilde{G}\left(e_{i}\right)\right)^{c}=\left\{\frac{x}{\left(\nu_{i}(x), \mu_{i}(x)\right)} \mid x \in U\right\}, \quad i=1,2, \cdots, n
$$

dimana $\nu_{i}(x)$ dan $\mu_{i}(x)$ merupakan suatu HFE atas $x$.

Definisi 3.8. [12] Suatu Complement dari himpunan lembut kabur hesitant diperumum $(\widetilde{G}, A)$ yang dinotasikan dengan $(\widetilde{G}, A)^{c}$ dapat didefinisikan sebagai

$$
(\widetilde{G}, A)^{c}=\left(\widetilde{G}^{c}, A\right),
$$

dimana $\widetilde{G}^{c}: A \rightarrow G H F^{U}$ pemetaan yang mendefinisikan $\widetilde{G}^{c}(e)=(\widetilde{G}(e))^{c}$ untuk setiap $e \in A$. 
Definisi 3.9. [12] Gabungan dari dua buah himpunan lembut kabur hesitant diperumum $(\widetilde{F}, A)$ dan $(\widetilde{G}, B)$ atas $U$ adalah himpunan lembut kabur hesitant diperumum $(\widetilde{H}, C)$, dimana $C=A \cup B$ dan untuk setiap $e \in C$ berlaku :

$$
\widetilde{H}(e)= \begin{cases}\widetilde{F}(e) & , j i k a e \in A-B, \\ \widetilde{G}(e) & , j i k a e \in B-A, \\ \widetilde{F}(e) \cup \widetilde{G}(e) & , j i k a e \in A \cap B .\end{cases}
$$

dan dinotasikan sebagai $(\widetilde{F}, A) \widetilde{\cup}(\widetilde{G}, B)=(\widetilde{H}, C)$.

Definisi 3.10. [12] Irisan dari dua himpunan lembut kabur hesitant diperumum $(\widetilde{F}, A)$ dan $(\widetilde{G}, B)$ dengan $A \cap B \neq \emptyset$ atas $U$, adalah himpunan lembut kabur hesitant diperumum $(\widetilde{J}, D)$, dimana $D=A \cap B$ dan untuk setiap $e \in D, \widetilde{J}(e)=\widetilde{F}(e) \cap \widetilde{G}(e)$.

Definisi 3.11. [12] Suatu operasi "AND" pada himpunan lembut kabur hesitant diperumum $(\widetilde{F}, A)$ dan $(\widetilde{G}, B)$ yang dinotasikan dengan $(\widetilde{F}, A) \wedge(\widetilde{G}, B)$, dapat didefinisikan sebagai

$$
(\widetilde{F}, A) \wedge(\widetilde{G}, B)=(\widetilde{J}, A \times B),
$$

dimana $\widetilde{J}(\alpha, \beta)=\widetilde{F}(\alpha) \cap \widetilde{G}(\beta)$ untuk setiap $(\alpha, \beta) \in A \times B=\{(a, b) \mid$ $a \in A, b \in B\}$.

Definisi 3.12. [12] Suatu operasi "OR" pada himpunan lembut kabur hesitant diperumum $(\widetilde{F}, A)$ dan $(\widetilde{G}, B)$ yang dinotasikan dengan $(\widetilde{F}, A) \vee(\widetilde{G}, B)$, dapat didefinisikan sebagai

$$
(\widetilde{F}, A) \vee(\widetilde{G}, B)=(\widetilde{O}, A \times B),
$$

dimana $\widetilde{O}(\alpha, \beta)=\widetilde{F}(\alpha) \cup \widetilde{G}(\beta)$ untuk setiap $(\alpha, \beta) \in A \times B=\{(a, b) \mid$ $a \in A, b \in B\}$.

Teorema 3.13. Misalkan diberikan dua himpunan lembut kabur hesitant diperumum $(\widetilde{F}, A)$ dan $(\widetilde{G}, B)$ atas $U$, maka:

(1) $(\widetilde{F}, A) \widetilde{\cup}(\widetilde{F}, A)=(\widetilde{F}, A)$,

(2) $(\widetilde{F}, A) \widetilde{\cap}(\widetilde{F}, A)=(\widetilde{F}, A)$,

(3) $(\widetilde{F}, A) \widetilde{\cup} \widetilde{\Phi}_{A}=(\widetilde{F}, A)$,

(4) $(\widetilde{F}, A) \widetilde{\cup} \widetilde{\Omega}_{A}=\widetilde{\Omega}_{A}$,

(5) $(\widetilde{F}, A) \widetilde{\cup}(\widetilde{G}, B)=(\widetilde{G}, B) \widetilde{\cup}(\widetilde{F}, A)$,

(6) $(\widetilde{F}, A) \widetilde{\cap}(\widetilde{G}, B)=(\widetilde{G}, B) \widetilde{\cap}(\widetilde{F}, A)$.

\section{Aplikasi Himpunan Lembut Kabur Hesitant Diperumum}

Chen Bin [12] memperkenalkan suatu algoritma yang digunakan untuk pengambilan keputusan dari permasalahan dengan menggunakan tabel perbandingan dari suatu himpunan lembut kabur yang mendasari operasi dari himpunan lembut kabur hesitant diperumum. Algoritma pengambilan keputusan pada himpunan lembut kabur hesitant diperumum dapat diberikan sebagai berikut : 
(1) Masukkan himpunan $\mathrm{A} \subseteq$ E yang merupakan himpunan parameter pilihan dari investor.

(2) Bentuk himpunan lembut kabur hesitant diperumum.

(3) Operasikan himpunan lembut kabur hesitant diperumum.

(4) Mempertimbangkan reduksi dari himpunan lembut kabur intuitionistik yang diperoleh dari himpunan lembut kabur hesitant diperumum dan disajikan dalam bentuk tabel.

(5) Buat tabel perbandingan dari derajat keanggotaan dan non keanggotaan dari hasil reduksi himpunan lembuut kabur hesitant diperumum dengan entri $a_{i}=$ $\Sigma b_{j}$ dimana

$$
b_{j}= \begin{cases}1 & , \text { jika } x_{k} \geq x_{t}, \\ 0 \quad, \text { jika } x_{k}<x_{t} .\end{cases}
$$

dengan $i=1,2, \cdots, m$ dan $j, k, t=1,2, \cdots, n$ dan $x_{k}, x_{t}$ merupakan entri-entri pada tabel reduksi dari himpunan lembut kabur hesitant diperumum

(6) Hitung tabel Score derajat keanggotaan dan non keanggotaan dengan mengurangkan jumlah baris dan kolom pada tabel perbandingan dari derajat keanggotaan dan non keanggotaan .

(7) Hitung score akhir dengan pengurangan score derajat keanggotaan dan non keanggotaan.

(8) Cari score maximum, jika score maximum terdapat pada baris ke- $i$ maka $x_{i}$ merupakan pilihan terbaik.

\section{Kesimpulan}

Dari pembahasan pada BAB III dan BAB IV dapat disimpulkan bahwa:

(1) Himpunan lembut kabur hesitant diperumum merupakan perluasan dari teori himpunan kabur hesitant diperumum dengan himpunan lembut.

(2) Misalkan $(F, A)$ dan $(G, B)$ merupakan dua himpunan lembut kabur hesitant diperumum. Berikut adalah definisi operasi-operasi pada himpunan lembut kabur hesitant dan sifat-sifatnya:

a) Suatu komplemen dari himpunan lembut kabur hesitant diperumum $(\widetilde{G}, A)$ yang dinotasikan dengan $(\widetilde{G}, A)^{c}$ dapat didefinisikan sebagai

$$
(\widetilde{G}, A)^{c}=\left(\widetilde{G}^{c}, A\right),
$$

dimana $\widetilde{G}^{c}: A \longrightarrow G H F^{U}$ pemetaan yang mendefinisikan $\widetilde{G}^{c}(e)=(\widetilde{G}(e))^{c}$ untuk setiap $e \in A$.

b) Operasi "AND"

$$
(\widetilde{F}, A) \wedge(\widetilde{G}, B)=(\widetilde{J}, A \times B),
$$

dimana $\widetilde{J}(\alpha, \beta)=\widetilde{F}(\alpha) \cap \widetilde{G}(\beta)$ untuk setiap $(\alpha, \beta) \in A \times B=\{(a, b) \mid a \in$ $A, b \in B\}$.

c) Operasi "OR"

$$
(\widetilde{F}, A) \vee(\widetilde{G}, B)=(\widetilde{O}, A \times B),
$$


dimana $\widetilde{O}(\alpha, \beta)=\widetilde{F}(\alpha) \cup \widetilde{G}(\beta)$ untuk setiap $(\alpha, \beta) \in A \times B=\{(a, b) \mid a \in$ $A, b \in B\}$.

d) Operasi gabungan.

Gabungan dari dua himpunan lembut kabur hesitant diperumum $(\widetilde{F}, A)$ dan $(\widetilde{G}, B)$ atas $U$ adalah himpunan lembut kabur hesitant diperumum $(\widetilde{H}, C)$, dimana $C=A \cup B$ dan untuk setiap $e \in C$ berlaku:

$$
\widetilde{H}(e)= \begin{cases}\widetilde{F}(e) & , \text { jika } e \in A-B, \\ \widetilde{G}(e) & , j i k a e \in B-A, \\ \widetilde{F}(e) \cup \widetilde{G}(e) & , \text { jika } e \in A \cap B .\end{cases}
$$

dan dinotasikan sebagai $(\widetilde{F}, A) \widetilde{U}(\widetilde{G}, B)=(\widetilde{H}, C)$.

e) Operasi irisan.

Irisan dari dua himpunan lembut kabur hesitant diperumum $(\widetilde{F}, A)$ dan $(\widetilde{G}, B)$ dengan $A \cap B \neq \emptyset$ atas $U$, adalah himpunan lembut kabur hesitant diperumum $(\widetilde{J}, D)$, dimana $D=A \cap B$ dan untuk setiap $e \in C, \widetilde{J}(e)=$ $\widetilde{F}(e) \cap \widetilde{G}(e)$.
f) i. $(\widetilde{F}, A) \widetilde{\cup}(\widetilde{F}, A)=(\widetilde{F}, A)$,
ii. $(\widetilde{F}, A) \widetilde{\cap}(\widetilde{F}, A)=(\widetilde{F}, A)$,
iii. $(\widetilde{F}, A) \widetilde{\cup} \widetilde{\Phi}_{A}=(\widetilde{F}, A)$,
iv. $(\widetilde{F}, A) \widetilde{\cup} \widetilde{\Omega}_{A}=\widetilde{\Omega}_{A}$,
v. $(\widetilde{F}, A) \widetilde{\cup}(\widetilde{G}, B)=(\widetilde{G}, B) \widetilde{\cup}(\widetilde{F}, A)$,
vi. $(\widetilde{F}, A) \widetilde{\cap}(\widetilde{G}, B)=(\widetilde{G}, B) \widetilde{\cup}(\widetilde{F}, A)$.

(3) Untuk mengambil suatu keputusan pada suatu permasalahan yang mempertimbangkan beberapa nilai-nilai derajat keanggotaan dan non keanggotaan dapat diselesaikan dengan menggunakan himpunan lembut kabur hesitant diperumum.

\section{Ucapan Terima kasih}

Penulis mengucapkan terima kasih kepada Bapak Admi Nazra, Ibu Nova Noliza Bakar, Ibu Lyra Yulianti, Ibu Des Welyyanti dan Ibu Yanita yang telah memberikan masukan dan saran sehingga makalah ini dapat diselesaikan dengan baik.

\section{Daftar Pustaka}

[1] Zadeh, L.A. 1965. Fuzzy Sets. Information and Control. Vol.8, pp 338 - 353

[2] Mizumoto, M and Tanaka, K. 1976. Some Properties of Fuzzy Sets of Type-2. Information and Control. Vol.31, pp $312-340$

[3] Dubois, D and Prade, H. 1980. Fuzzy Sets and Systems: Theory and Applications. Kluwer Academic. New York

[4] Atanassov, K.T. 1986. Intuitionistic Fuzzy Sets. Fuzzy sets and system. Vol.20, No.1, pp $87-96$

[5] Torra, V. 2010. Hesitant Fuzzy Sets Intenational Journal of Intelligent Systems. Vol.25, No.6, pp $529-539$ 
[6] Torra, V and Narukawa, Y. 2009. On Hesitant Fuzzy Sets and Desicion.International Jurnal of Intelligent Systems. Vol.25, No.6, pp 529 - 539

[7] Qian, G., Wang, H and Feng, X.Q. 2013. Generalized Hesitant Fuzzy Sets and Their Application in Desicion Support System.Knowledge-Based Systems. Vol.37, pp $357-365$

[8] Maji, P. K, Biswas, R dan Roy, A. R. 2001.Fuzy Soft Sets. Journal of Fuzzy Mathematics. Vol.9, No.3, pp $589-602$

[9] Molodtsov, D. 1999.Soft Set Theory - First Results. Computers and Mathematics with Aplication. Vol.37, No. 4-5, pp 19 - 31

[10] Xia, M and Xu, Z. 2011. Hesitant Fuzzy Information Aggregation in Decision Making. International Journal of Aproximate Reasoning. Vol.52, No.3, pp 395 $-407$

[11] Majumdar, P and Samanta, S.K. 2010. Generalized Fuzzy Soft Sets. Computers and Mathematics with Applications. Vol.59, pp 1425 - 1432

[12] Chen, B. 2016. Generalized Hesitant Fuzzy Soft Sets. Italian Journal of Pure And Applied Mathematics. Vol.36, pp 35 - 54 